\title{
() $\Theta \Theta$ movimento dos secundaristas brasileiros e o momento sofístico: uma nova história começa a ser contada $^{1}$
}

\author{
Tatiane da Silva* \\ Nathan Crick $^{* *}$
}

\begin{abstract}
Resumo: A partir das proposições de Arendt, delineamos o momento sofístico como um instante no qual a intersecção entre os termos riqueza, liberdade e poder possibilita aos indivíduos se engajarem na esfera política permitindo assim que influencie nas decisões. O objetivo deste trabalho é argumentar que o momento orquestrado pelos estudantes brasileiros pode ser considerado também um momento sofístico tal qual o vimos acontecer no século de Péricles, o que evidencia a necessidade de uma formação que abarque uma pedagogia retórica para que esse momento seja aproveitado em sua plenitude. As ações do movimento secundarista evidenciaram o peso da comunicação que demanda uma educação retórica, a qual inclui não só a formação na palavra em seu sentido dialógico e persuasivo, mas também raciocínio e deliberação, capacidades tão caras ao desenvolvimento do ethos democrático, por sua vez imprescindível para a edificação plena de um modo democrático de vida.
\end{abstract}

Palavras-chave: Momento sofista. Educação. Movimento secundarista. Retórica. Kairós

\footnotetext{
${ }^{1}$ A pesquisa contou com apoio da Fundação de Amparo à Pesquisa do Estado de São Paulo (FAPESP).

* Doutora em Educação Escolar pela Universidade Estadual Paulista Júlio de Mesquita Filho (UNESP). Professora Colaboradora na Faculdade de Filosofia, Ciências e Letras de Ribeirão Preto (USP). Professora da Rede Municipal de Ensino de Ribeirão Preto. E-mail: tathisilvausp@gmail.com ORCID: https://orcid.org/0000-0002-8943-2779

** Doutor em Comunicação pela University of Pittsburgh (PITT). Professor associado na Texas A\&M University. E-mail: crick@tamu.edu ORCID: https://orcid.org/0000-0002$5490-588 X$
} 
O movimento dos secundaristas brasileiros e o momento sofístico: uma nova história começa a ser contada

\title{
Brazilian high school students' movement and the sophistical moment: a new story begins to be told
}

\begin{abstract}
Drawing from the propositions of Arendt this work delineates the sophistical moment as an instant in which the intersection between the terms wealth, freedom and power enables individuals to engage in the political sphere thus allowing them to influence decisions. The aim of this work is to argue that the moment orchestrated by the Brazilian students can also be considered a sophistical moment as we have seen it happen in the century of Pericles, thus evidencing the necessity of a formation that embraces a rhetorical pedagogy. The actions of the high school movement evidenced the significance of communication, thus demanding a rhetorical education, which includes not only the formation of the word in its dialogical and persuasive sense, but also reasoning and deliberation. Those capacities are so important for the development of the democratic ethos which is indispensable for the full building of a democratic way of life.
\end{abstract}

Keywords: Sophistical moment. Education. High school movement. Rhetoric. Kairos

\section{Movimiento de los secundarios brasileños y el momento sofístico: una nueva historia comienza a ser contada}

Resumen: A partir de las proposiciones de Arendt, delineamos el momento sofístico como un instante en el que la intersección entre los términos riqueza, libertad y poder permite a los individuos participar en la esfera política, lo que les permite influir en las decisiones. El objetivo de este trabajo es argumentar que el momento orquestado por los estudiantes brasileños también puede considerarse un momento sofístico como lo hemos visto en el siglo de Pericles, lo que evidencia la necesidad de una formación que abarque una pedagogía retórica. Las acciones del movimiento secundario evidenciaron el peso de la comunicación, exigiendo así una educación retórica, que incluye no solo la formación de la palabra en su sentido dialógico y persuasivo, sino también el razonamiento y la deliberación, así como las capacidades para el desarrollo del espíritu democrático, para su desarrollo. indispensable para la plena construcción de un modo de vida democrático.

Palabras-clave: Momento sofista. Educacion. Movimiento de los secundaristas. Retórica. Kairos 


\section{Introdução}

A cidade de São Paulo tornou-se, nos últimos meses de 2015, o palco de uma onda enorme de protestos de estudantes secundaristas ${ }^{2}$. Os paulistanos tornaram-se testemunhas dos confrontos travados entre os manifestantes e a polícia que tentava reprimir o movimento. $\mathrm{O}$ confronto foi o último ato de um processo de ações desferidas pelos estudantes em resposta à proposta de reorganização do ensino projetada pelo governo estadual. ${ }^{3}$

Em setembro de 2015, o então governador do Estado de São Paulo, Geraldo Alckmin, anunciou a transformação de 754 escolas em unidades de ciclo único, as quais seriam responsáveis por fornecer separadamente a educação dos anos iniciais ( $1^{\circ}$ ao $5^{\circ}$ ano); dos anos finais do Ensino Fundamental $\left(6^{\circ}\right.$ ao $9^{\circ}$ ano); e também o Ensino Médio. Concomitantemente à transformação das escolas em ciclos únicos, o projeto incluía o fechamento de 94 escolas estaduais e o remanejamento para outras unidades de ensino de mais de 300 mil estudantes.

A justificativa dada pelo governo estadual para a implantação de tal projeto se baseava no argumento de "melhor organização por separação de idade" com foco na "qualidade do processo escolar" (PEDROSO; GOMES, 2015). Entretanto, como ressalta Marcus Vinicius Pó (2015) não era possível, por meio de uma leitura atenta do projeto proposto pelo governo, concluir que a divisão das escolas por ciclos iria refletir na melhora do desempenho escolar dos estudantes.

A proposta de reorganização escolar foi marcada desde a sua elaboração até o seu anúncio em cadeia televisiva pelo que Pablo Ortellado (2015) chamou de uma "ausência de discussão" da decisão do Estado entre professores, pais e estudantes que iriam ser afetados por esse projeto.

\footnotetext{
2 Nome dado aos estudantes que estão cursando o Ensino Médio, anteriormente denominado Segundo Grau, e que compreende o nível de ensino posterior ao Ensino Fundamental.

${ }^{3}$ Para maiores informações e relatos ver a obra de Campos; Medeiros e Ribeiro (2016).
} 
A negativa de abertura de diálogo pelo governo com os envolvidos é explicitada por Ortellado (2015) numa narrativa angustiante de ações realizadas pela comunidade escolar após o anúncio da proposta. Num primeiro momento, "o sindicato dos professores organizou protestos, porém eles foram ignorados". Um segundo ato veio da parte dos estudantes secundaristas que iniciaram protestos em suas vizinhanças, porém eles também foram ignorados.

Em 9 de novembro de 2015, a resposta para a negativa do governo em dialogar com a comunidade escolar foi a ocupação por dezenas de estudantes da Escola Estadual de Diadema na região metropolitana de São Paulo. Duas semanas após a primeira ocupação, mais de 200 escolas estavam ocupadas por milhares de jovens estudantes, fazendo com o que o movimento tomasse a forma do que Ortellado (2015) qualificou como um "imenso protesto", o qual deu voz à insatisfação dos estudantes com a qualidade do ensino oferecido.

Se num primeiro momento a luta dos estudantes poderia ser identificada com uma reação contra o fechamento das escolas, conforme o movimento se ampliava, intensificando-se assim a discussão e os debates, as reivindicações dos estudantes secundaristas se tornaram mais complexas e aprofundadas, como ilustrado na fala do estudante Fabrício Ramos (2015): "além da garantia de que os que participaram do movimento não serão retaliados, a luta agora é pela melhoria da educação nas escolas e o aumento da participação na administração". ${ }^{4}$ O clima de insatisfação também marca a fala de outra estudante, Glória Maria Brito dos Santos (2015): "salas superlotadas, aulas vagas, escolas sem laboratórios, sem cultura, sem conhecimento, o ensino e a estrutura de nossas escolas públicas são precários a ponto de acabar o ano e o aluno não ter aprendido plenamente nada".

O movimento de ocupações das escolas pelos estudantes secundaristas trouxe para o centro das discussões não apenas a

\footnotetext{
${ }^{4}$ Os relatos dos estudantes provêm de entrevistas concedidas a jornais, blogs e revistas no dia 9 de Dezembro de 2015 num momento de abertura da imprensa para os relatos dos jovens envolvidos nas ocupações. As entrevistas estão reunidas na \#ocupaestudantes.
} 
precarização do ensino público brasileiro, mas também o anseio dos jovens estudantes pela participação nas decisões políticas acerca da educação, mostrando a governantes e educadores, por meio de suas ações nas escolas ocupadas, a demanda por uma formação mais complexa do que a atualmente ofertada e a possibilidade de uma nova dinâmica de organização do tempo e dos conteúdos escolares. O relato da estudante Brenda Meira (2015) nos fornece um retrato bem acurado do que vimos argumentando: "além das aulas de matérias convencionais como geografia, história, sociologia, entre outras", os estudantes realizaram aulas de dança, teatro, culinária, yoga; aconteciam debates, aulas, palestras e atividades.

Para ilustrar a insatisfação dos jovens estudantes com a grande distância mantida pelo governo com a comunidade escolar nas decisões educacionais, Ortellado (2015) utilizou uma analogia empregada por Aristóteles há quatro mil anos quando abordou a tensão entre conhecimento técnico e o espírito da democracia, dizendo que "o convidado será um melhor juiz de uma festa que a cozinheira". Nesse contexto, para Ortellado (2015), quando empregamos os termos dessa analogia para analisar a satisfação dos estudantes secundaristas com a educação brasileira, eles estariam a passar fome ou insatisfeitos com as migalhas oferecidas pelo governo.

Podemos dizer que os estudantes secundaristas brasileiros poderiam ser identificados aos também "famintos" indivíduos da classe média ascendente de Atenas no século V a.C., os quais estavam também insatisfeitos com o banquete servido pela educação aristocrática e ansiavam, assim como os secundaristas brasileiros, por uma educação que lhes fornecesse um instrumento efetivo de participação nas decisões públicas que afetavam diretamente suas vidas. Quem melhor servia o banquete naquela época era os Sofistas que, por meio de uma pedagogia retórica, possibilitava ao indivíduo o entendimento e o uso consciente do instrumento essencial, o lógos, a palavra, para a efetiva participação política na discussão provocada pela emergência do que chamaremos de "momento sofístico". 
Considerando a exposição acima, o objetivo deste trabalho é argumentar que o momento orquestrado pelos estudantes brasileiros pode ser considerado também um momento sofístico tal qual vimos acontecer no século de Péricles, evidenciando assim a necessidade de uma formação que abarque uma pedagogia retórica para que esse momento seja aproveitado em sua plenitude. Procuraremos mostrar que a proximidade do cenário atual brasileiro com o cenário ateniense revela a existência do que os gregos antigos qualificavam como kairós, um momento oportuno, no qual um novo caminho se abre e as pessoas são capazes de se mostrarem e fazerem parte da narrativa da história.

O momento sofístico possibilita aos indivíduos se engajarem na esfera política permitindo assim que influenciem nas decisões; por intermédio do lógos eles alcançam o poder de atuarem em conjunto com vistas a um fim compartilhado.

\section{Definindo o momento sofístico}

Quando designamos o tempo de atuação dos Sofistas na polis grega com a palavra "momento" ao invés de o denominarmos por "era" ou "época", não temos por intenção minimizar as circunstâncias em torno do surgimento desses pensadores. Uma vez que nossos dicionários definem a palavra "momento" como ocasião precisa em que sucedem ou se dão certas circunstâncias ou um espaço de tempo indeterminado, geralmente de curta duração, serão mais nos termos "ocasião precisa" e "espaço de tempo indeterminado" que se pautarão nossas relações. ${ }^{5}$

A palavra "momento" carrega consigo um senso de kairós tal como os Sofistas, especialmente Górgias o concebia; um senso de urgência, de oportunidade e de brevidade, os quais caracterizam uma circunstância, uma ocasião precisa que aparece de repente num tempo em que a mudança e a indeterminação sobre as coisas e os fatos ao redor

\footnotetext{
${ }^{5}$ Conferir definição na página do dicionário Michaelis online: http://michaelis.uol.com.br/
} 
imperam e ameaça desaparecer com a mesma rapidez, seja por obsolescência ou supressão.

Podemos observar essa acepção do termo "momento" em duas passagens usadas para descrever os Sofistas. Para Rachel Ahern (2012, p. 31) os Sofistas habitaram um "momento histórico no qual a variedade de práticas sociais e literárias estava entrando em contato em Atenas", a "tradição poética arcaica cedendo sua autoridade cultural para novas formas poéticas da tragédia e da comédia, para novas formas de prosa, de historiografia e oratória, e para os emergentes discursos/disciplinas da filosofia e da retórica". Poulakos (1995) ressalta que "por conta de seu momento na história, podemos dizer que os Sofistas foram os beneficiários e benfeitores de uma era de exuberância cultural, expansão política, crescimento econômico, experimentação intelectual e expressão artística robusta".

Nas duas passagens supracitadas, caracterizar os Sofistas como habitantes de um "momento" traz a conotação de que eles estavam no meio de um tempo de rápida mudança e transição, quando as coisas poderiam se transformar de uma maneira ou de outra em qualquer instante, porém também carrega a ideia de que essas forças poderiam se interceptar para iluminar radicalmente novas possibilidades e fazer possível novas práticas.

Christian Meier (1990, p. 17) captura a atmosfera do momento sofistico desta forma: "tudo parece acontecer com uma incrível rapidez, em poucas décadas tempestuosas - especialmente em Atenas". Repentinamente, os homens se encontravam surpreendentemente numa "nova situação"; as "regras e os conceitos tradicionais foram considerados deficientes, ou pelo menos já não tinham muito a oferecer aos espíritos animados que tinham que confiar em seus próprios recursos para lidar com tudo".

Para utilizarmos uma analogia para representar esse momento sofístico marcado pela ideia de kairós, a imagem seria como se o tempo cronológico regido por Cronos, o deus do tempo, nos conduzisse como se estivéssemos imersos em um rio pelo qual somos levados por seu fluxo; o 
O movimento dos secundaristas brasileiros e o momento sofístico: uma nova história começa a ser contada

tempo kairótico, ligado ao kairós, seriam os lagos para os quais o curso do rio seria temporariamente desviado e nos desse a possibilidade de nadar à nossa maneira, alterando, mesmo que por um instante, por um momento, o pré-determinado fluxo das águas. O momento kairótico é um estranho instante que rompe e perturba a continuidade do tempo (PETRUZZI, 2001, p. 351).

O momento sofístico pode ser também classificado como revolucionário. Entretanto, consideraremos, assim como Arendt (1965, p. 18) ressaltou, que ser qualificado como revolucionário não necessariamente implica o desejo de derrubar uma ordem estabelecida, e muito menos de ser liberado de um estado de opressão, como historicamente vimos associando essa palavra mais com tirania do que com democracia.

Pelo contrário, revolução é "inextricavelmente vinculada com a noção de que o curso da história repentinamente se torna novo, que uma nova história, uma história não conhecida ou nunca antes contada está prestes a acontecer". Consequentemente, a revolução não pode ocorrer quando a violência ou a mudança política simplesmente rearranja as peças sobre o mesmo tabuleiro; a revolução apenas ocorre quando alguém é capaz de mudar as regras do jogo e imaginar uma sequência de novos movimentos sobre um tabuleiro diferente. Como Arendt (1965, p. 25) explica, "apenas quando a mudança ocorre num sentido de um novo começo, onde a violência é usada para constituir uma forma completamente diferente de governo", ou seja, para acarretar a formação de um novo corpo político, e "onde a liberação da opressão tenha por objetivo ao menos a constituição de liberdade, nós podemos falar de revolução".

O momento sofistico, então, surge no despertar dessa mudança revolucionária, habitando o que Arendt (1965, p. 36) chama de "estranho pathos (paixão) pela novidade" que as pessoas experimentam quando percebem que uma nova história está para ser contada e na qual irão ter uma parte na narração. Neste sentido, o momento sofístico pode ser 
considerado um tempo no qual as pessoas procuram a possibilidade de contar sua própria história antes que a liberdade que se abre lhes escape.

Como a maioria dos momentos revolucionários, o momento sofístico não surge por intermédio de qualquer projeto particular, mas sim sob a intersecção de riqueza, liberdade e poder. Expliquemos melhor.

Até mesmo as duas maiores reformas democráticas ocorridas em Atenas, primeiro com Solón em 594 a.C. e depois com Clístenes em 508 a. C., não foram medidas políticas progressivas apresentadas para fazer oposição a um determinado status quo. Elas foram respostas criativas a períodos de convulsão violenta causada pelo fraturamento da velha ordem aristocrática, do fosso crescente que se abria entre ricos e pobres e do surgimento de uma poderosa nova classe mercante.

Incumbidos da elaboração das reformas constitucionais que deveriam dissipar uma previsível violência futura, ambos Sólon e Clístenes, concederam poderes políticos a uma ampla classe de cidadãos, mais por um caso de necessidade do que por um compromisso com princípios democráticos. Como Robert Wallace (2008, p. 72) bem observa "Sólon não estava tentando politizar o povo"; "em uma situação perigosa a qual ameaça irromper em violência", os mediadores como regra não fazem concessões de imediato poder político ao povo que não está demandando por esse poder. Entretanto, mesmo que cada uma dessas radicais concessões tenha sido feita fora de necessidades políticas, elas lançaram a inteira cultura política para dentro de um novo ambiente, tornando obsoleta grande parte da sabedoria convencional que permeava esse meio.

$O$ resultado desses esforços para criar um balanço de forças mais harmonioso no século VI a. C. foram concretizados na concepção de uma areté política, ou seja, uma formação não mais confinada àqueles com sangue aristocrático, mas alcançável por qualquer cidadão. Como Werner Jaeger (1946, p. 287) enfatiza, "agora a comunidade era composta por membros de uma cidade, não por membros de poucas famílias nobres".

$\mathrm{O}$ resultado dessa mudança da nobreza para uma relativamente mais inclusiva classe média trouxe consigo uma série de alterações, mudanças aceleradas com o aumento da alfabetização e a disponibilidade 
O movimento dos secundaristas brasileiros e o momento sofístico: uma nova história começa a ser contada

de textos escritos que fizeram as leis cada vez mais transparentes e a arte e o conhecimento cada vez mais disponíveis.

Edward Schiappa (2003, p. 30) ilustra essas mudanças descrevendo-as como o tempo quando "a prosa escrita e oral desafiou a poesia, explicações antropocêntricas ou 'científicas' desafiaram as tradições teístas e a democracia radical desafiou as mais elitistas formas de governo". Poulakos (1995, p. 13) caracteriza o século V a. C. como o período no qual "a aristocracia da nobreza cedia a uma democracia de cidadãos; a aristocracia dos mitos perdia sua autoridade para a democracia dos argumentos públicos; a aristocracia dos oráculos recuava ante a democracia das leis humanas". Foi no alvorecer desse momento revolucionário que Atenas vivenciava que os Sofistas entraram em cena; um momento revolucionário caracterizado pela intersecção entre riqueza, liberdade e poder.

Para se entender a importância que o termo "riqueza" tem para o momento sofistico, devemos antes distingui-lo da relação direta que muitos fazem dele com o sentido de "propriedade", visando caracterizar patrimônios particulares. Como Arendt (1958, p. 61) ressalta "riqueza e propriedade, longe de ser a mesma coisa, são de uma natureza inteiramente diferente". Propriedade é algo tangível, representando uma parte do mundo que alguém possui e a qual separa o terreno público do privado. Tanto na Grécia quanto na primitiva América, propriedade significava "nada mais do que ter um local numa parte particular do mundo e, por conseguinte, pertencer ao corpo político".

Quando nos referimos ao termo "riqueza" como algo que caracteriza o momento sofístico, o tomamos em contraste ao significado de propriedade. Riqueza, nessa acepção, representa mais uma capacidade, especificamente uma capacidade para adquirir e consumir objetos ou ganhar acesso a acontecimentos e manifestações, os quais, de alguma maneira se relacionam com o processo de vida biológico, de sobrevivência e prazer, de trabalho e de entretenimento. Em resumo, riqueza representa "alguma coisa a ser usada e consumida não importando quantas expectativas individuais isso possa sustentar" (ARENDT, 1958, p. 69). 
Nesse sentido, um indivíduo pode então possuir propriedade, entretanto, ter pouca riqueza. Por exemplo, alguém que herdou um grande patrimônio e junto um grande débito. Por outro lado, um indivíduo pode ter uma enorme riqueza, mas nenhuma propriedade. Exemplo disso, é alguém que possui muitos investimentos, mas nenhum lugar para chamar de casa. O que pretendemos afirmar é que riqueza é fluida enquanto propriedade não, a última é então naturalmente associada com estabilidade de linhagens aristocráticas e a primeira associada com a dramática ascensão de empresários.

Para compreendermos melhor a importância da riqueza no momento sofistico, partiremos de uma das críticas principais que Platão endereçou aos Sofistas: a prática de receber pagamentos pelos seus ensinos. Embora Platão tenha redigido essa crítica em termos da questão da virtude, afirmando que o conhecimento não é um bem a ser vendido, seu objetivo era se referir ao "crescimento da classe média, uma classe definida por riqueza recém-adquirida que ocupava o ponto intermediário entre a nobreza latifundiária e os servos" (POULAKOS, 1995, p. 15).

A ascensão de Atenas como um centro de comércio internacional, particularmente de azeite, prata, cerâmica, joias e essências, abriu mais oportunidade para uma ampla camada da população do que a proporcionada pela velha economia agrária dos tempos homéricos. A possessão de riqueza permitiu então aos indivíduos, antigamente marginalizados, adquirirem propriedade, podendo assim, reivindicarem poder político como cidadãos na democracia ateniense.

Colocando a objeção de Platão dentro desse contexto, ela pode ser vista como uma "resistência aristocrática em tornar disponíveis as habilidades de governança a qualquer indivíduo, independentemente de nascimento, àqueles que poderiam pagar por elas" (JARRAT, 1998, p. 84). O que é importante aqui não é um padrão absoluto de riqueza, mas um relativo. A mudança da propriedade (linhagem tradicional) para a riqueza (capacidade consumatória) significou que enquanto as barreiras para a completa cidadania permaneciam altas para os atenienses, as barreiras tornaram-se fluidas e capazes de serem transpostas por indivíduos 
O movimento dos secundaristas brasileiros e o momento sofístico: uma nova história começa a ser contada

afortunados o suficiente para entrar na posse da riqueza. Foi para esta classe de "recém-ricos" que os Sofistas forneceram seus ensinamentos.

O que fez do programa de ensino sofístico mais do que um simples aprendizado da excelência de administrar os negócios domésticos (Protágoras, 318e) e dos Sofistas mais do que consultores de gestão para a economia doméstica (oikós) foi o aumento da riqueza anteriormente apontado desenvolvido ao lado e em colaboração com um aumento da liberdade política na cidade-estado (polis). Entretanto, devemos ressaltar que essas duas esferas se relacionaram diretamente, pois a riqueza nos negócios domésticos era a chave para o desbloqueio da liberdade política.

Como Arendt (1958, p. 30-31) observa "era uma questão clara que o domínio das necessidades da vida nos negócios domésticos foi a condição para a liberdade da polis". Liberdade política era então reservada para os chamados "iguais", para aqueles que não estavam "sujeitados às necessidades da vida ou pelo comando de outro" (ARENDT, 1958, p. 32). Uma vez permitido o acesso à esfera política, esses indivíduos foram hábeis em tirar vantagem de uma liberdade incomparável, não possibilitada por nenhum sistema político anterior.

Quando pensamos em liberdade nos dias de hoje, nós, em grande medida, relacionamos esse termo a um sentido negativo como ser livre de determinada coerção. Contudo, como Josiah Ober (2005, p. 295-296) ressalta, é importante entender que os atenienses "interpretaram liberdade mais em termos de um direito positivo do cidadão em engajar-se na atividade política mais do que em sua 'liberdade negativa' da interferência governamental".

Dito de outra forma, a "liberdade central que os atenienses amavam era isēgoria: o direito do cidadão em discursar na soberana assembleia de pessoas" (OBER, 2005, p. 296). Considerar esse direito como um verdadeiro tesouro devia-se à razão prática de que o acesso à liberdade política então permitia a esses indivíduos a habilidade em influenciar decisões políticas que se relacionariam diretamente nos seus status econômicos. 
Ressaltamos, assim como Arendt esclarece, que não deveríamos reduzir a paixão pela liberdade política simplesmente a termos econômicos; liberdade traz consigo seus próprios bens implícitos que são valorizados independentemente da sua habilidade em serem traduzidos em ganho material. Isso se dá porque a liberdade política não é simplesmente um meio para um fim; mas é um fim em si mesmo - a capacidade de aparecer perante os outros como si mesmo e começar algo novo.

A associação contemporânea a nós de política como um tipo de manipulação partidária crassa distorce o significado original de política, que é para Arendt (2005, p. 108), sinônimo da própria liberdade: “o significado de política é liberdade”. Liberdade (e suas concomitantes recompensas de esplendor e fama) "é relacionado ao terreno político, o qual é a esfera pública na qual todo mundo pode aparecer e mostrar quem ele realmente é; para afirmar sua própria opinião, para ser capaz de se mostrar, ser visto e ouvido pelos outros" (ARENDT, 2005, p. 14).

Finalmente, talvez,a característica que melhor defina o momento sofistico seja o poder. E mais uma vez, torna-se imprescindível distinguir a maneira que Arendt (1970, p. 45) define poder, relacionando o termo com violência ou autoridade. Violência refere-se ao esforço da força física ou a canalização da força natural para algum fim instrumental com o intuito de fabricar ou destruir, enquanto autoridade representa o "reconhecimento inquestionável por aqueles que são chamados a obedecer". Desta forma, a ameaça de violência na forma de coerção geralmente pode produzir uma frágil, entretanto, temporária forma de autoridade para comandar. Em contradistinção, poder corresponde a "habilidade humana de não apenas atuar, mas atuar em conjunto" (ARENDT, 1970, p. 44).

Uma vez pautados nas reflexões de Arendt, podemos dizer que seria uma ideia errada falar sobre poder de um indivíduo isolado ou então o poder de um amuleto mágico, ou o poder de uma espada ou até mesmo de um deus. Isso se dá porque poder "nunca é a propriedade de um individuo; ele pertence a um grupo e permanece existindo contanto que o grupo permaneça unido" (ARENDT, 1970, p. 44). Consequentemente, quando nos referimos a alguém e dizemos que "ele está no poder", na 
O movimento dos secundaristas brasileiros e o momento sofístico: uma nova história começa a ser contada

realidade nós estamos nos referindo que ele "tem sido autorizado por certo número de pessoas a atuar em nome delas" (ARENDT, 1970, p. 44). Podemos dizer, então, que poder refere-se especificamente à existência de algum entendimento compartilhado entre as pessoas - produzido por intermédio da comunicação - que as permitem atuar em coordenação com outros por meio de consentimento voluntário. Neste sentido, poder é o que "mantém o terreno público, o espaço potencial de aparência entre os homens que atuam e os que falam"; poder é o terreno e o produto da política.

O momento sofistico era então caracterizado pelo poder de modo diferente do poder que existia na Grécia homérica ou nos impérios da Persa e do Egito. Não podemos negar que o poder existia nessas sociedades, contudo, os canais por intermédio dos quais esse poder era expresso estavam altamente circunscritos por hierarquias fixas e tradição sedimentária em que apenas uma pequena elite tinha a liberdade para iniciar algo novo.

Entretanto, depois das reformas democráticas implementadas por Clístenes, um novo tipo de espaço político apareceu no mundo grego denominado polis, um lugar que representava o que Ober (2005, p. 25) chama de "o poder mediador e integrativo de comunicação entre os cidadãos"; na Atenas de meados do século V a.C. "ser um efetivo orador era a chave do poder" (GUTHRIE, 1971, p. 44).

Não há como negar o fato de que o poder em Atenas estava diretamente relacionado à arte de bem falar, todavia, ao se tomar essa informação de maneira isolada, ela tende a reinscrever a atuação da pedagogia Sofista como somente tendo por objetivo o ensino das táticas persuasivas e a noção de que o poder é uma força abstrata a ser possuída e empunhada por um individuo isolado. O poder não é um prêmio a ser vencido por um discurso inteligente; o poder é produzido dentro do que Arendt (1958, p. 7) chama de "condição de pluralidade" que faz a ação coletiva possível. O poder é constituído por um ato de discurso que provê um lógos, um relato ordenado e consecutivo da medida das coisas, capaz 
de organizar a experiência compartilhada daquela pluralidade e direcionar sua ação futura.

O fato histórico que melhor ilustra a verdadeira natureza do poder ateniense nos termos que vimos argumentando, um poder menos expresso nas forças das armas do que na capacidade dos atenienses, foi o ato dos gregos em abandonar Atenas e esperar a frota da Pérsia no estreito de Salamina, sob o conselho de Temístocles. Apesar de os persas terem demonstrado seu próprio poder por reunir e organizar o maior exército já visto no mundo antigo, sua capacidade para se adaptarem, para mudarem o curso e reagirem a eventos inesperados foi limitada por seu sistema político monárquico o qual repousava sobre a completa deferência do julgamento do Grande Rei.

Em contrapartida, os gregos fizeram da estratégia militar um assunto de discussão e debate - meio pelo qual o lógos de Temístocles levou a melhor. $\mathrm{O}$ que os gregos perceberam naquele momento foi que devido ao seu sistema político democrático, o estado ironicamente "devia sua salvação a um homem de notáveis poderes intelectuais" (JAEGER, 1946, p. 289). Considerando o que vimos discutindo, podemos afirmar que os gregos perceberam que a fonte de seu poder não provinha dos deuses nem da força de seu exército, mas sim de um lógos humano e racional, de um relato fundamentado que foi articulado por um indivíduo e era produto de uma cultura democrática dedicada ao cultivo da mente assim como do corpo.

Sob o alvorecer dessa revolução política e do crescimento econômico, uma nova esfera de liberdade emergiu e logo provou ser capaz de aproveitar e canalizar um enorme poder; um poder constituído pelo lógos. Como Poulakos (1995, p. 15) acertadamente ressaltou, o novo regime político grego era melhor descrito não como "aristocrático nem democrático, mas sim logocrático", um regime que "enfatiza a primazia do lógos como meio circulante entre seres humanos e ao mesmo tempo constituindo os seres humanos e o mundo".

É nesse ato da grande epopeia grega que os Sofistas emergiram, abarcando como parte essencial do seu programa de ensino "nada menos 
O movimento dos secundaristas brasileiros e o momento sofístico: uma nova história começa a ser contada

do que a formação da mente para pensar", pois apenas uma mente pensante pode produzir um lógos ordenado e persuasivo (SCHIAPPA, 2003, p. 47). $\mathrm{O}$ que os jovens que buscavam os ensinamentos sofistas, personificados por Platão na figura de Hipócrates ansiavam não era se tornar um hábil orador per si, mas adquirir o domínio do lógos que poderia lhes permitir constituir e direcionar o poder nos negócios privados e na cidade, uma necessidade que os Sofistas entraram em cena para preencher clamando ensinar a areté.

Qual é então a principal contribuição dos Sofistas para o terreno político? Certamente nós podemos creditar aos Sofistas o fato de serem os precursores e inovadores nas artes da retórica, ou o que Arendt (2005, p. 67) define como "a arte da persuasão, a mais alta e verdadeira arte política”. Ao oferecerem a formação retórica, os Sofistas permitiram que uma camada maior de cidadãos dominasse as técnicas de elaborar discursos persuasivos, fato que diretamente incidiu na pluralidade de opiniões postas para julgamento na assembleia sobre determinado assunto.

Nesse fato está, segundo Arendt (2005, p. 167) o genuíno impacto dos Sofistas na esfera política, fruto menos de um intento consciente e mais de uma consequência indireta de seu ensinamento e prática. Arendt (2005, p. 167-168) ressalta que "a extraordinária habilidade [dos Sofistas] na argumentação é de importância secundária para a primeira criação bem sucedida pela polis de um terreno político". O fator crucial não era que um indivíduo poderia agora mudar os argumentos e afirmar proposições por si só, mas sim, obter a "habilidade de verdadeiramente ver os assuntos de vários ângulos - o que é, politicamente - o resultado de que as pessoas entenderam como assumir as várias perspectivas possíveis fornecidas pelo mundo real", a partir do qual um único e mesmo tópico pode ser considerado e em que cada tópico, "apesar de sua unidade, aparece em uma grande diversidade de pontos de vista". A capacidade de persuadir e influenciar os outros, que era como os cidadãos da polis interagiam politicamente, presumiu um "tipo de liberdade que não estava irrevogavelmente ligada, seja mental ou fisicamente, à própria opinião de alguém ou ao seu ponto de vista". 
O momento sofístico representa aquele espaço frequentemente frágil no qual essa liberdade política torna-se disponível para uma nova classe de cidadãos, uma liberdade que se constitui não somente por persuadir ou falar, mas de ver as coisas de diferentes perspectivas, de ver o mundo como uma pluralidade e de afirmar a própria opinião como valorosa de consideração para servir como base para o poder. Os Sofistas surgiram para servir as necessidades dessa classe que emergia, cultivando as capacidades da mente e desenvolvendo as artes do discurso e ação necessários para conseguir riqueza e acessar o poder político. Fazendo isso, eles também fizeram real a promessa da política, que consiste em continuamente expandir a esfera na qual os indivíduos possam aparecer diante dos outros e mostrar ser o que eles realmente são.

\section{O movimento dos secundaristas paulistas: um momento sofístico}

Como já tivemos oportunidade de evidenciar neste trabalho a discussão acerca das mudanças ocorridas na Grécia no século V a.C., por mais que utilizemos a palavra "momento" para caracterizar um acontecimento particular que por um tempo escreve uma nova narração no curso da história, sabemos que as circunstâncias que acorrem para propiciar o surgimento desses momentos são delineadas por anos, décadas ou até mesmo séculos antes que tal momento venha à tona. De maneira similar ao ocorrido no momento sofístico grego, guardadas as devidas particularidades de ambas as sociedades, o gérmen do momento sofístico no Brasil brotou décadas antes em solo brasileiro e ainda vem dando seus frutos.

Na década correspondente aos anos de 2001 a 2011, o Brasil apresentou taxas consideráveis de crescimento econômico, as quais aliadas a alguns fatores, tais como: a diminuição das desigualdades de rendimentos, os programas de transferência de renda, a estabilização econômica da última década e a expansão de crédito, foram capazes de aumentar os rendimentos e o padrão de consumo de muitas famílias 
O movimento dos secundaristas brasileiros e o momento sofístico: uma nova história começa a ser contada

(BARROS et al., 2010). ${ }^{6}$ Ainda há muita discussão sobre se devemos ou não classificar esses indivíduos que tiveram um aumento nos rendimentos de "nova classe média", termo utilizado por Neri (2010) em seus trabalhos que abordam a questão por uma perspectiva econômica. Considerando que o objetivo de nosso artigo é outro e alertados sobre o "perigo de conceituar" esses indivíduos que tiveram um aumento na participação da distribuição de renda no país como uma "nova classe média", uma vez que muitos ainda vivem em condições precárias, não temos por intenção discorrer se o termo é ou não aplicável. Pautaremos nossa análise no ponto de concordância entre os autores que analisam o tema, a saber, que o "aspecto central da mudança é a possibilidade de consumo" (SARAIVA et al, 2015, p. 54).

De acordo com Neri (2010), cerca de 29 milhões de pessoas ingressaram naquilo que ele chama "nova classe média" entre 2003 e 2009 , totalizando assim aproximadamente $50,5 \%$ da população brasileira. A renda domiciliar absoluta desses indivíduos ficou compreendida entre $\mathrm{R} \$ 1.064,00$ e $\mathrm{R} \$ 4.561,003$ e a renda per capita entre $\mathrm{R} \$ 214,00$ e $\mathrm{R} \$$ 923,00, concentrando em meados de 2009 mais de 46,24\% do poder de compra dos brasileiros, comparado com as classes $\mathrm{AB}$, que concentravam $44,12 \%$ do total (SARAIVA et al, 2015. p. 53).

É a partir desse quadro que podemos delinear as relações entre o momento sofístico grego e o brasileiro concretizado pelo movimento dos estudantes secundaristas, evidenciando assim o primeiro termo que caracteriza essa relação: riqueza. A utilização desse termo, tomando por base a argumentação de Arendt, não diz respeito nem exclusivamente nem prioritariamente à aquisição a bens de consumo, pois o movimento se deu em localidades de poder aquisitivo bastante heterogêneo. Nossa ênfase é

\footnotetext{
${ }^{6}$ Segundo o caderno 4 da série "Vozes da Nova Classe Média", resultado de um estudo encomendado pela Secretaria de Assuntos Estratégicos da Presidência da República, com participação do IPEA (Instituto de Pesquisa Econômica Aplicada), do CNI (Confederação Nacional da Indústria) e do Instituto Data Popular, entre os anos de 2001 a 2011, ocorreu um aumento de $33 \%$ na renda per capita do país. Ainda nesse período, a População Economicamente Ativa (PEA) aumentou de 123 milhões para 146 milhões de pessoas, com um crescimento $1,7 \%$ ao ano. Ver http://www.cartacapital.com.br/economia/o-perfil-danova-classe-media-9232.html
} 
no acesso a informações, acontecimentos e manifestações que se relacionam à vida social, biológica e política. Não há como negar, a partir dos dados expostos por Neri (2010) que uma significativa parcela da população brasileira ganhou essa capacidade de acesso nas últimas décadas. Essa riqueza mais fluida alcançada por essa população é concretizada devido à ampliação da possibilidade de acessar - se não de adquirir - meios eletrônicos tais como celulares, computadores com internet e eletrodomésticos (SARAIVA et al, 2015. p. 53).

$\mathrm{O}$ acesso a essas tecnologias modifica substancialmente a vida desses indivíduos que passam a fazer parte de uma rede maior de pessoas interconectadas e expostas a todo o momento a um grande fluxo de informações. Com seu consentimento ou não, especialmente nas mídias sociais, esses indivíduos tomam conhecimento de fatos e notícias vindas de todas as partes do mundo e que antes lhes eram, em grande parte, desconhecidos uma vez que se restringiam ao noticiário e aos jornais impressos.

Diante dessa nova realidade que se apresenta a esses indivíduos, não é de se espantar que, como ocorreu com a "nova classe média" da Grécia clássica do século V a.C., presenciamos um aumento na busca por instrução. Apesar da escolaridade da maioria da população brasileira não ser satisfatória se comparada a outros países em desenvolvimento ${ }^{7}$, houve um aumento nos anos de estudo de chefes de família e seus cônjuges, assim como o acesso ao ensino superior, fazendo com que $60 \%$ dos estudantes universitários no Brasil hoje sejam provenientes dessa camada da população conforme dados do Instituto Data Popular (SARAIVA et al, 2015. p. 53).

A busca pela educação por esses indivíduos nos dois casos, não só evidencia o anseio pela manutenção da riqueza alcançada, mas também uma conscientização de que é por intermédio da educação que eles

\footnotetext{
${ }^{7}$ No ranking da OECD (Organização para a Cooperação e Desenvolvimento Econômico) que analisa a educação em 36 países, Brasil está na penúltima posição, à frente somente do México, e atrás de países como Chile, África do Sul e Turquia. Ver http://www.oecdbetterlifeindex.org/topics/education/ acesso em 21/09/2016.
} 
O movimento dos secundaristas brasileiros e o momento sofístico: uma nova história começa a ser contada

poderão ser incluídos no mercado de trabalho como também de que a instrução é a base para o segundo termo do nosso momento sofístico, a participação numa liberdade política com vistas a defenderem sua nova posição no cenário brasileiro.

Segundo Moisés (1990, p. 185), na década de 1990, podia-se registrar o interesse do eleitorado por uma participação política efetiva, o que se daria por meio do sufrágio nos períodos eleitorais. A mais evidente expressão do "sentimento de indignação moral" era concretizada no voto de protesto que visava punir partidos e governos que se mostrassem incapazes de cumprir as expectativas apresentadas publicamente. Desde então, com o avanço tecnológico e o advento das redes sociais, viabilizando maior acesso a informações e notícias, houve significativa ampliação na discussão sobre temáticas políticas. Entretanto, a participação dos brasileiros continua, em grande medida, restrita aos períodos eleitorais; essa apatia reflete a falta de preparo dos indivíduos para atuarem no processo democrático.

Ainda que os documentos oficiais que regem a educação nacional preconizem a formação do cidadão democrático, ativo e crítico, nota-se que a escola tem falhado em fornecer satisfatoriamente as habilidades para que os indivíduos se engajem na atividade política, para que usufruam da sua liberdade no sentido por nós já apresentado. Mesmo diante da ausência de formação política, o que se soma aos obstáculos postos pelos governos para incentivar a participação e a discussão além dos períodos eleitorais, nos últimos anos, começa a surgir uma demanda pelo exercício dessa liberdade, pela valorização da opinião das pessoas nos processos de deliberação acerca de políticas públicas.

O próprio movimento dos estudantes secundaristas é um exemplo concreto de ações nesse âmbito; movimentos de outra natureza e situados em contextos diferentes, mas igualmente indicativos do anseio pela liberdade de opinião, foram as Jornadas de Junho de 2013, a greve dos caminhoneiros de 2018 e as greves gerais contra os cortes no Ensino Superior ocorridas no decorrer de 2019. 
Pautando-nos na análise do movimento dos estudantes secundaristas, ressalta-se que durante os mais de 30 dias de ocupação, os prédios escolares foram transformados pelos alunos em lugares de debate, deliberação e atividades culturais, fazendo desses locais verdadeiras ágoras. A ágora era o local onde palpitava durante todo o dia a vida política, social e econômica da polis. Eram nesses mercados que os homens de negócio debatiam cotações e ao mesmo tempo os interessados pela política discutiam a ordem do dia da próxima assembleia (GLOTZ, 1946, p. 254-255).

Vistos como verdadeiras ágoras erigidas em tempos modernos, os prédios escolares eram os locais no qual palpitava o coração do movimento dos secundaristas: suas assembleias. Essas reuniões marcadas por debates e diálogos permitiram aos estudantes efetuarem decisões e realizarem ações coordenadas que iam desde a organização de equipes responsáveis pela segurança e limpeza do prédio, atendimento à imprensa, preparo da alimentação e organização dos alojamentos até a articulação dos protestos nas ruas e a divulgação de cartas abertas à imprensa e ao público contendo as principais reivindicações do grupo. O relato de Bruno Bocchini (2015) evidencia o clima de ação conjunta que se instaurou entre os estudantes: as ações do grupo eram deliberadas e votadas por intermédio de assembleias frequentemente organizadas.

Durante sua permanência nas unidades de ensino, os estudantes instauraram um clima intenso de debates, discussão política e atividades culturais que fizeram parte do currículo provisório instituído pelos alunos. Os relatos de Simone Ishibashi e Odete Cristina (2015) detalham alguns elementos contemplados pelo currículo organizado pelos estudantes: havia aulas sobre "o combate ao racismo e a questão negra, a luta das mulheres e dos trabalhadores". Temas polêmicos e marginalizados pelo debate escolar e que dizem respeito aos problemas vividos pelos estudantes em seu cotidiano foram abordados durante as ocupações, instaurando uma abertura para a discussão pouco vista no ambiente escolar, como apontado pela estudante Brenda Meira (2015): muitas vezes queríamos realizar "debates com assuntos que nos diziam respeito, que eram polêmicos, atuais e fomos 
O movimento dos secundaristas brasileiros e o momento sofístico: uma nova história começa a ser contada

reprimidos", e agora com os "alunos à frente da escola, está acontecendo tudo isso, estamos tendo uma noção mais ampla de tudo o que acontece no nosso dia-a-dia e ao nosso redor".

Além das atividades curriculares organizadas pelos alunos, durante as ocupações, os estudantes também se preocuparam em abrir a escola para a participação da comunidade na qual ela está inserida. Bryan Aftimus (2015), presidente do grêmio estudantil da Escola Estadual Caetano de Campos, ressalta que as atividades organizadas pelos alunos nas ocupações iam de "reuniões sobre o futuro da unidade a atividades culturais e sociais abertas à comunidade". A sinalização dos alunos para a integração da comunidade no ambiente escolar foi além da mera participação enquanto espectadora do processo educacional; em algumas falas como a de Fabrício Ramos (2015), que afirmou que "a eleição do diretor pela comunidade é uma de nossas propostas", podemos notar a reivindicação dos estudantes perante a administração estadual de uma participação maior da comunidade nas decisões que dizem respeito à gestão escolar e que afetam diretamente a vida dos estudantes, uma maior liberdade nos termos aqui discutidos.

A diversidade de atividades e conhecimentos abarcados pelos currículos instituídos pelos secundaristas não apenas revelou a necessidade de uma melhoria na qualidade da educação ofertada a eles, como também a urgência em se organizar uma escola mais voltada para as reais necessidades do aluno. A fala de Eloiza Oliveira (2015) é categórica nesse sentido: "eu acho que além da luta pela educação de qualidade" é necessária uma "luta pela adequação da educação". Para o secundarista Francisco Júlio (2015) as ocupações permitiram o afloramento de algo muito importante para os estudantes, qual seja a possibilidade de se "discutir a escola que queremos".

Se num primeiro momento, o movimento de ocupações tinha como reivindicação principal o impedimento do fechamento das escolas, conforme as discussões e os debates foram tomando corpo nos mais de 30 dias de mobilizações, os secundaristas ampliaram a pauta do movimento e 
lançaram nas redes sociais com ampla divulgação nacional um manifesto que unificava os anseios dos estudantes (FERNANDES, 2015).

No documento lançado a público, os secundaristas enfatizavam que estavam em luta por uma educação pública de qualidade, sendo assim reivindicavam a revogação imediata do projeto de reorganização do ensino em São Paulo; que nenhuma escola fosse fechada ou dividida; que nenhum professor fosse demitido; que não houvesse mais salas de aula superlotadas; e por fim, que nenhum aluno, pai, professor ou cidadão que participou de alguma forma das ocupações fosse perseguido (FERNANDES, 2015).

Após várias semanas de truculentos protestos e centenas de escolas ocupadas, no dia 4 de dezembro de 2015, o governador do Estado de São Paulo, Geraldo Alckmin, veio a público e decidiu suspender a reorganização escolar, afirmando que "o ano de 2016, que seria o ano de implantação do projeto, seria o ano de aprofundar o diálogo" (G1, São Paulo, 17/12/2015). Cabe ressaltar que o recuo de Alckmin em sua decisão de efetivar a reorganização escolar em São Paulo coincidiu com a publicação de uma pesquisa pelo Datafolha da popularidade do governador revelando o menor índice já registrado desde sua posse em 2014 (G1 São Paulo, 17/12/2015). Os alunos seguiram mobilizados mesmo após o anúncio de suspensão da reorganização escolar, porém planejaram saídas de forma conjunta entre os dias 18 e 21 de dezembro de 2015.

O movimento dos secundaristas brasileiros revela uma particularidade em comum com o momento de abertura política vivenciado pelos Sofistas: a possibilidade dos até então excluídos das discussões se mostrarem e terem suas vozes ouvidas e suas reivindicações tomadas em conta no debate político. Tal fato é reflexo da interseção que vem se delineando em nosso país entre os termos "riqueza, liberdade e poder", caracterizando assim o momento sofistico.

A parcela de liberdade nas discussões de políticas públicas e do próprio processo político que se abriu desde a eclosão do movimento dos secundaristas brasileiros vem tomando contornos cada vez mais fortes 
O movimento dos secundaristas brasileiros e o momento sofístico: uma nova história começa a ser contada

conforme os anos passam tornando cada vez mais nítido o terceiro elemento que compõe o momento sofístico: o poder.

Como vimos, o movimento secundarista evidenciou para a sociedade a importância do exercício do poder para que suas reivindicações e suas vozes fossem ouvidas e consideradas no âmbito da tomada de decisões políticas.

E esse poder, nos termos aqui apresentados, evidenciou-se pela capacidade dos alunos para atuarem em conjunto, seja para organizarem as ocupações, para deliberarem sobre os objetivos do movimento, para discutirem as ações a serem realizadas e até mesmo os termos do acordo final. Isto ocorre quando os educandos são imersos em uma situação retórica, tal como postulado pelos Sofistas, situações em que se devem deliberar conjuntamente em busca da solução para um problema compartilhado, utilizando o recurso da comunicação. São experiências assim que possibilitam aos alunos criarem hábitos de deliberação, pensamento crítico, debate, diálogo, invenção. Este é o corolário de uma pedagogia retórica que se dedica a desenvolver as capacidades necessárias para o cidadão atuar de maneira plena em uma democracia.

Uma educação bancária, como Paulo Freire (1987, p. 33) acertadamente caracterizou, tal qual se adota na maioria das escolas brasileiras, não tem possibilidade de desenvolver e cultivar o ethos democrático, conjunto de capacidades que possibilitam aos indivíduos, não importando a variedade de seus contextos de vida, o envolvimento em atividades de cooperação, ação inteligente, deliberação e atuação coletiva (BERNSTEIN, 2000).

A educação bancária ofertada pelo ensino tradicional na maioria das nossas escolas concebe o educador como sujeito exclusivo a conduzir os educandos pela memorização mecânica dos conteúdos; essa educação não é capaz de fornecer as ferramentas necessárias para que o aluno participe ativamente no processo de ensino e, como cidadão, na construção de uma sociedade democrática. Nessa concepção, o aluno é tomado como sujeito passivo, vazio e inerte, cuja tarefa é apenas assimilar, memorizar e guardar os conteúdos transmitidos pelo professor. Os conhecimentos 
"dissertados" pelo professor são entendidos como algo "petrificado" pela narrativa, estático e sem relação dinâmica com a realidade. A educação "é puro treino, é pura transferência de conteúdo, é quase adestramento, é puro exercício de adaptação ao mundo" (FREIRE, 2000, p. 101).

O ethos democrático só poderá ser desenvolvido em uma sala de aula dialógica, como propõem Freire e a pedagogia crítica de Henri Giroux, Ira Shor e Stanley Aronowitz; uma sala em que o estudante aprenda a questionar, agir, fazer perguntas e ser reconhecido como um agente de mudança (ARONOWITZ, 2008). Contudo, não há como desenvolver o ethos democrático e preparar o cidadão para uma atuação ativa no campo social, político e cultural, sem considerarmos, juntamente com a educação dialógica, a necessidade da formação no lógos, tal qual se define no âmbito de uma pedagogia retórica.

Fundamentada nas proposições Sofistas, a pedagogia retórica propõe o ensino das técnicas de persuasão, raciocínio, criação, estilo, por meio das quais, os alunos aprendem os elementos necessários para atuar como cidadãos ativos e conscientes, voltados a um regime democrático em que os rumos da coletividade sejam discutidos por todos. É nesse contexto que a deliberação tem papel essencial, uma vez que diz respeito à "natureza de juízos comuns" sobre o que é melhor ou pior, quando várias linhas de ação possíveis se apresentam para o julgamento coletivo (DEWEY, 1922/2003, p. 179).

Nesse mundo do possível, em que se apresentam aos indivíduos várias perspectivas, a retórica é o melhor instrumento para a formação da identidade de pensamento que leve o indivíduo, bem como a coletividade, a experiências mais ricas e emancipadoras, por intermédio do debate, da troca de perspectivas e da deliberação conjunta, como ocorrida dentro das assembleias nas ocupações.

Crick (2015) ilustra a pedagogia retórica com uma metáfora utilizada por Dewey: a sala de aula retórica deve propiciar os contextos deliberativos próprios de uma sociedade democrática. É como se nos tornássemos conscientes de intempéries e problemas, tais como recifes e tempestades que podem surgir quando traçamos um itinerário de viagem 
O movimento dos secundaristas brasileiros e o momento sofístico: uma nova história começa a ser contada

em um barco a vela. Segundo Crick (2015b, p. 178), o educador é o responsável por trazer esses obstáculos para a sala de aula, tomando como ponto de partida os estudantes, utilizando seus argumentos, exemplos, crenças, hábitos e emoções. A deliberação é efetivada quando os vários "fatores em ação" se harmonizam, quando o mar se apresenta calmo e com ventos favoráveis (DEWEY, 1922/2003, p. 181).

A urgência deste momento sofístico que estamos atravessando evidencia aos professores a necessidade de uma postura Sofista a qual exige a habilidade em cultivar nos estudantes o lógos, entendido não apenas como discurso, mas também como raciocínio e deliberação para que possam fazer suas pautas e reivindicações serem tomadas em consideração na narrativa da história brasileira.

\section{Considerações Finais}

Delinear o momento sofístico a partir das proposições de Arendt nos possibilita pensar que o período no qual o movimento secundarista se efetivou carregava em si um senso de kairós, uma oportunidade de efetivação de uma ação conjunta na busca de um objetivo comum: o não fechamento das escolas. Conforme o movimento se intensificou a pauta foi ampliada, buscando-se assim uma maior participação de alunos e comunidade nas discussões políticas que dizem respeito à educação pública estadual.

Como ilustrado na mitologia grega, o deus Kairós é representado por um homem que possui asas nos pés e nas costas, equilibrando em uma de suas mãos uma balança sob uma navalha; possuindo cabelo apenas na parte da frente da cabeça, justificando a proverbial frase "agarrar a oportunidade pelo topete", o kairós apenas pode ser apreendido ou agarrado no momento certo, the right time. Os estudantes secundaristas souberam articular sua pauta e fazer com que suas reivindicações fossem asseguradas porque tiveram a capacidade de poder atuar em conjunto num momento propício; um momento em que há uma cultura política emergente possibilitada pela interseção entre riqueza, liberdade e poder. 
As ações do movimento secundarista evidenciaram o peso da comunicação demandando assim um currículo que preze por uma formação sofista, uma educação que possibilite aos indivíduos a capacidade de atuar em conjunto, de debater, de ver os assuntos por vários pontos de vistas e priorizar a condição de pluralidade que deve basear a formação dos consensos a respeito de qualquer assunto.

Desta feita, tal formação evidencia a necessidade da construção de uma sala de aula dialógica, tal como preconizada por Freire e, como argumentado neste artigo, uma pedagogia retórica baseada nos preceitos e ensinamentos dos Sofistas.

Não esperamos fazer desta nossa argumentação uma ode à educação antiga, muito menos incentivar a nostalgia da formação educacional própria de uma cultura passada; menos ainda idealizar o presente, que deve ser o alvo de nosso exame crítico. O que se busca é criar uma heurística por intermédio da qual possamos não apenas identificar momentos sofísticos na história, como também evidenciar a importância de prover aos indivíduos que povoam esse momento sofistico uma pedagogia retórica, a qual inclui não só a formação na palavra em seu sentido dialógico e persuasivo, mas também raciocínio e deliberação, capacidades tão caras ao desenvolvimento do ethos democrático, por sua vez imprescindível para a edificação plena de um modo democrático de vida.

\section{Referências}

AFTIMUS, B. Ocupação em escola tradicional de SP tem guardião, mascote e 'toboágua'. depoimento [01/12/2005]. São Paulo: G1. Entrevista concedida a Glauco Araújo. Disponível em http://g1.globo.com/saopaulo/noticia/2015/12/ocupacao-em-escola-tradicional-de-sp-temguardiao-mascote-e-toboagua.html acesso em 20/12/2015.

AHERN, R. Poetic speakers, sophistic words. American Journal of Philology. vol. 133, n. 1.p. 31-60, 2012. https://doi.org/10.1353/ajp.2012.0009 
O movimento dos secundaristas brasileiros e o momento sofístico: uma nova história começa a ser contada

ARENDT, H. Human Condition. Chicago: The University of Chicago Press, 1958.

ARENDT, H. On revolution. New York: Penguin Books, 1965.

ARENDT, H. On Violence. New York, Harcourt, Brace \& World, 1970.

ARENDT, H. The promise of politics. New York: Schocken Books, 2005.

ARONOWITZ, S. Against schooling: for an education that matters. Boulder, Colorado: Paradigm, 2008.

BARROS, R. CARVALHO, M. FRANCO, S. MENDONÇA, R. Determinantes da Queda na Desigualdade de Renda no Brasil. IPEA. Texto para discussão ${ }^{\circ}$ 1460, 2010.

BERNSTEIN, R.J. Creative democracy: the task still before us. American Journal of Theology \& Philosophy, v. 21, n. 3, p. 215- 228. 2000.

BOCCHINI, B. Estudantes de São Paulo ampliam pautas e querem discutir nova educação pública. Disponível em http://www.redebrasilatual.com.br/educacao/2015/12/apos-um-mes-deocupacao-das-escolas-estudantes-de-sp-continuam-nas-ruas-4923.html acesso em 10/12/2015.

CAMPOS, A. M.; MEDEIROS, J.; RIBEIRO, M. M. Escolas de luta. São Paulo: Veneta, 2016.

CRICK, N. Compor a vontade de poder: John Dewey sobre a educação retórica para uma democracia radical. Educação e Cultura Contemporânea, Rio de Janeiro, v. 12, n. 28, p. 164-183, 2015.

DEWEY, J. Human nature and conduct: an introduction to Social Psychology. The Middle Works of John Dewey, 1899-1924. In: BOYDSTON, Jo Ann (Org.). The collected works of John Dewey, 18821953. Volume 14: 1922. Carbondale: Southern Illinois University, 2003. 
FERNANDES, S. Em assembleia, estudantes decidem intensificar ocupações lançam manifesto. Disponível em http://www.redebrasilatual.com.br/educacao/2015/11/em-assembleiaestudantes-decidem-intensificar-ocupacoes-e-lancam-manifesto-3932.html acesso em 20/01/2016.

FREIRE, P. Pedagogia da indignação: cartas pedagógicas e outros escritos. São Paulo: Editora UNESP, 2000. https://doi.org/10.1590/S1414$\underline{32832001000100016}$

FREIRE, P. Pedagogia do oprimido. 17 ed. Rio de Janeiro: Paz e Terra, 1987.

G1. Justiça suspende reorganização escolar em São Paulo, diz Defensoria. Disponível em http://g1.globo.com/sao-paulo/escolasocupadas/noticia/2015/12/justica-suspende-reorganizacao-escolar-em-spdiz-defensoria.html Acesso e 18/12/2015.

GLOTZ, G. História econômica da Grécia. Lisboa: Edições Cosmos, 1946.

GUTHRIE, W. K. C. Os sofistas. Tradução de João Resende da Costa. 2. edição. São Paulo: Paulus, 2007.

ISHIBASHI, $\mathrm{S}$; CRISTINA, O. Os secundaristas deram exemplo e apontam luta por outro projeto de educação, 2015. Disponível em http://www.esquerdadiario.com.br/Os-secundaristas-deram-exemplo-eapontam-luta-por-outro-projeto-deeducacao?utm_source=newsletter\&utm_medium=email\&utm_campaign= Newsletter acesso em 15/12/2015.

JAEGER, W. Paideia: the ideals of Greek culture. Volume 1. Archaic Greece: the mind of Athenas. Translated by Gilbert Highet. Oxford: Basil Blackwell, 1946.

JARRAT, S. Rereading the sophists: classical rhetoric refigured. Illinois: Southern Illinois University, 1998. 
O movimento dos secundaristas brasileiros e o momento sofístico: uma nova história começa a ser contada

JÚLIO, F. Em assembleia, estudantes decidem intensificar ocupações e lançam manifesto. depoimento. [29/11/2015]. Entrevista concedida a Sarah Fernandes. Disponível em http://www.redebrasilatual.com.br/educacao/2015/11/em-assembleiaestudantes-decidem-intensificar-ocupacoes-e-lancam-manifesto-3932.html acesso em 20/01/2016.

MEIER. C. The Greeks discovery of politics. Harvard University Press, 1990.

MEIRA, B. Estudantes que dobraram o governador Geraldo Alckmin contam suas histórias. depoimento. [09/12/2015]. Entrevista concedida a Renato Guimarães. Disponível em http://www.brasilpost.com.br/renatoguimaraes/estudantes-contam-suas-historias_b_8742228.html acesso em $15 / 12 / 2015$.

MENDONÇA, R. Popularidade de Alckmin atinge pior marca, aponta Datafolha. Folha de São Paulo, Cotidiano, 04/12/2015. Disponível em http://www1.folha.uol.com.br/cotidiano/2015/12/1714813-popularidadede-alckmin-atinge-pior-marca-aponta-datafolha.shtml acesso em 20/01/2016.

MOISÉS, J. A.. Eleições, participação e cultura política: mudanças e continuidades. Lua Nova. n. 22. São Paulo, Dez. 1990. https://doi.org/10.1590/S0102-64451990000200007

NERI, M. C. A nova classe média: o lado brilhante dos pobres. Rio de Janeiro: FGV/CPC, 2010.

OBER, J. Aristotle's natural democracy. In: KRAUT, R.; SKULTETY, S. Aristotle's politics: critical essays. Lahan, MD: Rowman and Littlefield, 2005.

OLIVEIRA, E. Conheça os bastidores da ocupação das escolas de SP. depoimento. [14/12/2015]. Entrevista concedida a EBC Brasil. Disponível em http://www.ebc.com.br/educacao/2015/12/caminhos-da-reportagemtraz-bastidores-da-ocupacao-das-escolas-em-sp-assista acesso em 20/12/2015. 
ORTELLADO, P. Brazil's Students Occupy Their Schools to Save Them. The opinion pages. The New York Times, Nova Iorque, 15 dez. 2015. Disponível em http://www.nytimes.com/2015/12/16/opinion/brazilsstudents-occupy-their-schools-to-save-them.html?_r=0 acessado em $15 / 12 / 2015$.

PEDROSO, C. C. A.; GOMES, M. de O. Reorganização escolar: cenas de um filme conhecido, 2015. Disponível em www.cartaeducacao.com.br/artigo/reorganização-escolar-cenas-de-umfilme-conhecido/ acesso em 5/12/2015.

PETRUZZI, A.. P. Kairotic rhetoric in Freire's Liberatory Pedagogy. $J A C$, v. 21, n. 2, p. 349-381, 2001.

PLATÃO. Protágoras (ou Sofistas). In: PLATÃO. Diálogos I. Tradução de Edson Bini. São Paulo: EDIPRO, 2007b.

PÓ, M. V. Análise de Universidade Federal contesta reorganização escolar. depoimento. [dez. 2015]. Entrevista concedida a Paulo Saldaña e Victor Vieira no Jornal Estadão, Educação. Disponível em http://educacao.estadao.com.br/noticias/geral,analise-de-universidadefederal-contesta-reorganizacao-escolar-em-sp,10000003458 acesso em 20/12/2015.

POULAKOS, J. Sophistical rhetoric in Classical Greece. Columbia: University of South Carolina, 1995. https://doi.org/10.2307/358732

RAMOS, F. Estudantes de São Paulo ampliam pautas e querem discutir nova educação pública. depoimento. [09/12/2015]. Entrevista concedida a Bruno Bocchini. Disponível em http://www.redebrasilatual.com.br/educacao/2015/12/apos-um-mes-deocupacao-das-escolas-estudantes-de-sp-continuam-nas-ruas-4923.html acesso em 20/12/2015.

SANTOS, G. M. B. dos. \#ocupaestudantes: Nossa contrarreorganização é que organizou. depoimento. [09/12/2015]. Entrevista concedida à Redação do site de notícias Outras Palavras. Disponível em 
O movimento dos secundaristas brasileiros e o momento sofístico: uma nova história começa a ser contada

http://outraspalavras.net/blog/2015/12/09/ocupaestudantes-nossacontrarreorganizacao-e-que-organizou/ acesso em 21/12/2015.

SARAIVA, L. F. de O. S.; REZENDE, J. C. de O.; REIS, J. V. de S.; INÁCIO, M. D. ; SCHUCMAN, L. V. A "nova classe média": repercussões psicossociais em famílias brasileiras. Psicologia USP, v. 26, n. 1, p. 52-61, 2015. https://doi.org/10.1590/0103-6564D20140008

SCHIAPPA, E. Protagoras and logos: a study in Greek philosophy and rhetoric. 2. ed. Columbia: University of South Carolina, 2003.

WALLACE. R. Origins of democracy in Ancient Greece. University of California Press, 2008.

Data de registro: 08/08/2019

Data de aceite: 24/04/2020 